Original Research Article

\title{
The Study of Potential Antiviral Compounds from Indonesian Medicinal Plants as Anti-COVID-19 with Molecular Docking Approach
}

\section{Baiq Ressa Puspita Rizma*(C) \\ Agus Dwi Ananto}

Anggit Listyacahyani Sunarwidhi

Department of Pharmacy, Universitas Mataram, Mataram, West Nusa Tenggara, Indonesia

*email:

baiqressapuspitarizma@gmail.com
Keywords:

Anti-COVID-19

Docking

Indonesia

Medicinal plants

\begin{abstract}
Corona Virus Disease 2019 (COVID-19) is a new strain of coronavirus called SARS-CoV-2, which was identified in Wuhan, China, in December 2019. The rapid transmission of COVID-19 from human to human forced researchers to find a potent drug by setting aside the time-consuming traditional method in drug development. The molecular docking approach is one a reliable method to screening compound from chemical drug or by finding a compound from Indonesian herbal plants. The present study aimed to assess the potency of compounds from five medicinal plants as potential inhibitors of PLpro and 3CLpro from SARS-CoV-2 using molecular study. The molecular docking was performed using Protein-Ligand Ant System (PLANTS) to analyze the potential compounds by the docking score. Remdesivir triphosphate was used as a standard for the comparison of the test compounds. The docking score obtained from the docking of PLpro with native ligand, remdesivir triphosphate, curcumin, demethoxycurcumin, bisdemethoxycurcumin, luteolin, apigenin, quercetin, kaempferol, formononetin-7-O-glucuronide, andrographolide, and neoandrographolide were -111.441, -103.827, 103.609, -102.363, -100.27, -79.6655, -78.6901, -80.9337, -79.4686, 82.1124, -79.1789, and -97.2452, respectively. Meanwhile, docking score with 3CLpro for the same ligand were $-64.0074,-86.1811,-81.428$, $-87.1625,-78.2899,-73.4345,-70.3368,-71.5539,-68.4321,-72.0154,-$ 75.9777, and -93.7746. The docking score data suggest that curcumin was the most potential as a PLpro inhibitor, while neoandrographolide was the best as a 3CLpro inhibitor.
\end{abstract}

Received: May 28th, 2021

Accepted: June 13th, 2021

Published: June 30th, 2021

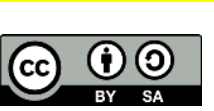

(C) 2021 Baiq Ressa Puspita Rizma, Agus Dwi Ananto, Anggit Listyacahyani Sunarwidhi. Published by Institute for Research and Community Services Universitas Muhammadiyah Palangkaraya. This is an Open Access article under the CC-BY-SA License (http://creativecommons.org/licenses/by-sa/4.0/). DOI: https:// doi.org/10.33084/jmd.v1i1.2307

\section{INTRODUCTION}

Corona Virus Disease 2019 (COVID-19) is a disease caused by the outbreak of SARS-CoV-2 infection, a new coronavirus strain 1 . Food and Drug Administration of America (US FDA) stated that there is still no specific drug to inhibit the virus until this paper was written. Only broad-spectrum antiviral such as remdesivir are used to treat the infection'. Remdesivir is a prodrug and nucleoside analog, as a prodrug remdesivir has two active metabolites such as remdesivir nucleoside (GS-441524) and remdesivir triphosphate (GS-443902) 3,4.
The rapid transmission of COVID-19 from human to human forces researchers to find a potent drug, including using natural sources as an alternative ${ }^{5}$. However, natural drug development has its limitation, including it is time-consuming. This limitation could be addressed by using the molecular docking approach ${ }^{6,7}$. Molecular docking is one of the in silico approaches used to design or select compounds that can be used as an inhibitor or an activator of a target protein, and it also assesses the mechanism of action in the molecular state ${ }^{8}$. 
As mentioned by the Indonesian Food and Drug Administration (BPOM Indonesia), several medicinal plants from Indonesia with antiviral activity can be used to treat COVID-19 patients, such as turmeric (Curcuma longa), curcuma (Curcuma xanthorrhiza), gale of the wind/meniran (Phyllanthus niruri), green chiretta/sambiloto (Andrographis paniculata), and guava (Psidium guajava) ${ }^{9}$. Some research has been done to prove the plants have potential secondary metabolite as an antiviral to support this statement. Curcumin, demethoxycurcumin, and bisdemethoxycurcumin in C. longa or C. xanthorrhiza have been shown to have an activity to inhibit 3C-like protease (3CLpro) and spike protein of SARS-CoV-2 in the in silico study. At the same time, another study also reported that curcumin affect $3 \mathrm{CL}^{\text {pro }}$ of SARS-CoV-2 in the in vitro research ${ }^{10,11}$. Based on in vitro study, quercetin in P. guajava was shown to inhibit SARSCoV-2 papain-like protease ( $\mathrm{PL}^{\text {pro }}$ ) with an $\mathrm{IC}_{50}$ of 8.6 $\mu \mathrm{M}^{12}$. Luteolin, apigenin, quercetin, and kaempferol in P. guajava also shown potency to inhibit 3CLpro of SARS-CoV-2 based on in silico study ${ }^{13}$. Based on another in silico study with AutoDock Vina, quercitrin in $P$. niruri, as well as andrographolide and neoandrographolide from $A$. paniculata, show the best potential as a 3CLpro SARS-CoV-2 inhibitor based on free energy acquisition ${ }^{14}$.

In the life cycle of SARS-Cov-2, two non-structural proteins have a crucial role. First, 3 CLpro plays a role in replicating polypeptides into functional proteins to multiply viruses ${ }^{15}$. The $3 \mathrm{CL}^{\text {pro }}$ plays a role in synthesizing replicas through proteolysis mechanisms, and viruses will use these replicas to construct structural proteins to multiply themself ${ }^{16}$. Meanwhile, PLpro serves as an essential virulence factor for the virus. The PL pro works by untying ISG15 from IRF3, thus inhibiting Interferon (I and III) formation, which serves to signal the immune system $^{17}$. This protein has the potential to be used as a target for treatment; in addition to genetic similarities between SARS-CoV (96\%) and SARS-CoV-2, 3CL pro and PLpro also has not undergone mutations such as D614G in viral spike proteins ${ }^{18}$. Based on this background, this study aims to assess the potency of compounds from five medicinal plants from Indonesia, as mentioned before, as a potential inhibitor of PLpro and 3CLpro from SARS-CoV-2, using a molecular docking approach.

\section{METHOD}

\section{Hardware and Software}

The hardware used was Asus notebook with Intel ${ }^{\circledR}$ Core $^{\mathrm{TM}}$ RAM 4.00 GB, Operation System Windows 10, 64-bit operating system. The software used was YASARA View 19.12.14 from YASARA Bioscience (http://www.yasara.org/), MarvinSketch 5.2.6 from ChemAxon

(https://chemaxon.com/products/marvin), and PLANTS (Protein-Ligand Ant System) 64-bit from Universität Tübingen (https://unituebingen.de/fakultaeten/mathematischnaturwissenschaftlichefakultaet/fachbereiche/pharmazie-undbiochemie/teilbereich-pharmazie-pharmazeutischesinstitut/pharmazeutische-chemie/pd-dr-texner/research/plants/).

\section{Ligands}

Ligands in this research were divided into two groups: test and standard ligand. The test ligands were curcumin (PubChem ID 969516), bisdemethoxycurcumin demethoxycurcumin (5469424), apigenin (5280443), luteolin (5280445), kaempferol (5280863), quercetin (5280343), formononetin-7-O-glucuronide (71316927), andrographolide (5318517), and neoandrographolide (9848024). The standard ligands were remdesivir triphosphate (56832906). The two-dimension structure of each ligand was obtained from the PubChem database (https://pubchem.ncbi.nlm.nih.gov/), then it was optimized into three-dimension using MarvinSketch to obtain the best conformation with the lowest energy.

\section{Receptors}

The receptors used in this study were SARS-CoV-2 PLpro (PDB ID 3E9S) and 3CLpro (5R7Y) ${ }^{19}$, which downloaded from Protein Data Bank (https://www.rcsb.org).

\section{Docking protocol}

Overall, the docking protocol used in this study was based on the docking protocol used by Purnomo et a ${ }^{20}$.

Preparation of target protein and native ligand

The target protein and native ligand preparation were carried out using YASARA View. The protein was obtained by deleting its native ligand in the PDB file (Figure 1). In contrast, the native ligand was obtained by deleting the protein from the PDB file (Figure 2). In 
this step, the protein and native ligand file were obtained in format protein.mol2 and ref_ligand.mol2.

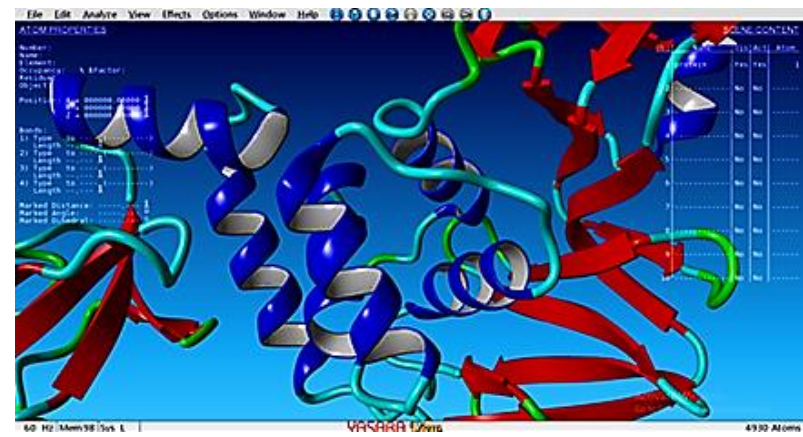

A

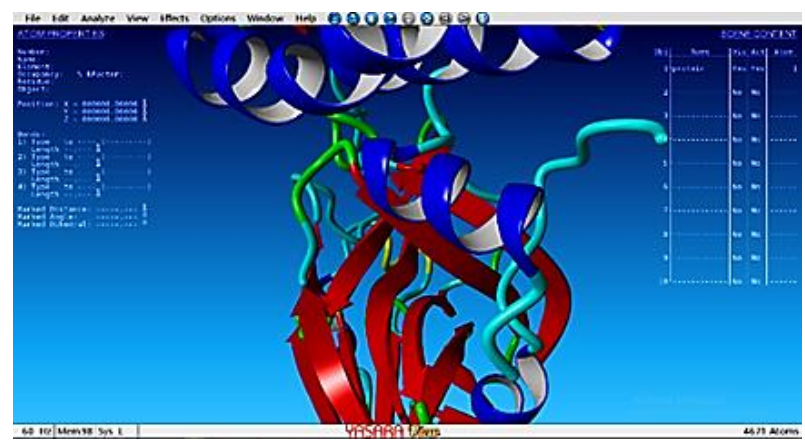

B

Figure 1. Three-dimension structure of (A) PLpro and (B) 3CLpro.

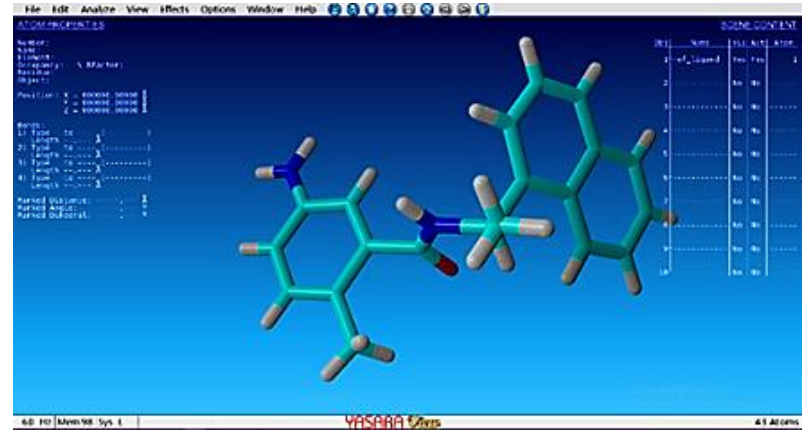

A

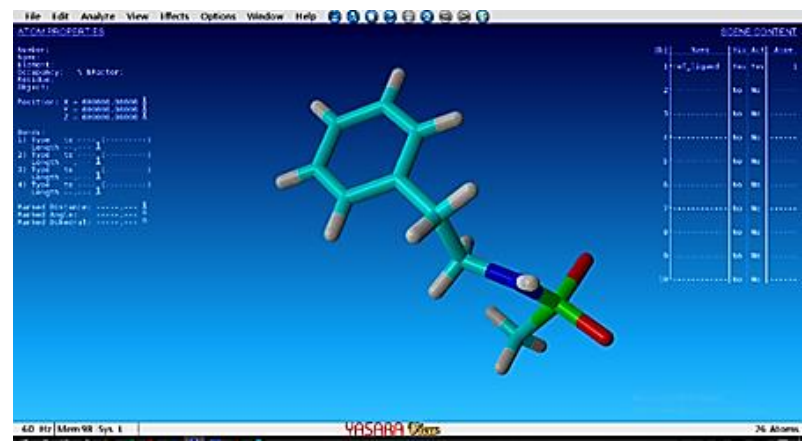

B

Figure 2. Three-dimension structure of (A) PLpro and (B) 3CLpro native ligand.

\section{Docking protocol validation}

Docking protocol validation aims to obtain a root median square deviation (RMSD) value. The RMSD value was asses using YASARA View by re-docking the native ligand to its protein. Docking protocols stated as a valid protocol if the RMSD value $<2 \AA^{21}$.

Test ligand docking

Docking was done using PLANTS by typing the commands in cmd.exe. The optimized test ligand was docked to the active site of both PLpro and $3 \mathrm{CL}^{\text {pro }}$. PLANTS will read the command that has been set before to obtain the best docking score of each test ligand. The final result of the docking score would be compared with the best score of the native ligand.

\section{Assessment}

The assessment was performed using a descriptive approach. The results from the docking process were the docking score of each interaction between the test ligand and target protein. The docking score indicates affinity between the ligand and target protein. The docking score was described as a negative value, meaning the test ligand had a good affinity and potential as the inhibitor of the target protein ${ }^{22}$. The test ligand was stated to had potential as the target protein inhibitor if the docking score was more negative than the docking score of remdesivir triphosphate.

\section{RESULTS AND DISCUSSION}

\section{Docking protocol validation}

The RMSD value of PLpro and its native ligand 5amino-2-methyl-N-[(1R)-1-naphthalen-1-

ylethyl]benzamide was $0.5707 \AA$, and the RMSD value of $3 \mathrm{CL}^{\text {pro }}$ with $\mathrm{N}$-(2-phenylethyl)methanesulfonamide was $1.5525 \AA$ (Figure 3). Based on the RMSD value, the docking protocol was valid because the value was less than $2 \AA$.

\section{Curcuma longa and Curcuma xanthorrhiza}

The docking score between curcumin, demethoxycurcumin, and bisdemethoxycurcumin with both PL pro and $3 \mathrm{CL}^{\text {pro }}$ was shown in Figure 4. The interaction shows that curcumin had the best potency as a PLpro inhibitor because the docking score (103.609) was almost the same as remdesivir triphosphate (-103.827). Another in silico research using AutoDock Vina claimed curcumin acted best as PLpro inhibitor among four other targets like angiotensin-converting enzyme 2 (ACE2), 
transmembrane serine protease 2 (TMPRSS2), RNAdependent RNA polymerase (RdRp), and 3CLpro, with the free binding energy $(\Delta \mathrm{G})$ of $-8.45 \mathrm{kcal} / \mathrm{mol}$, which was less than those ACE2 $(-7.99 \mathrm{kcal} / \mathrm{mol})$, TMPRSS2 $(-7.19 \mathrm{kcal} / \mathrm{mol}), \operatorname{RdRp}(-5.3 \mathrm{kcal} / \mathrm{mol})$, and 3CLpro $(-$ $7.24 \mathrm{kcal} / \mathrm{mol})^{23}$.

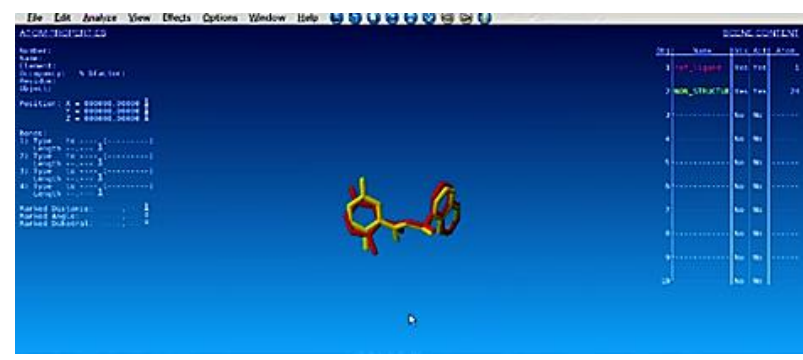

A

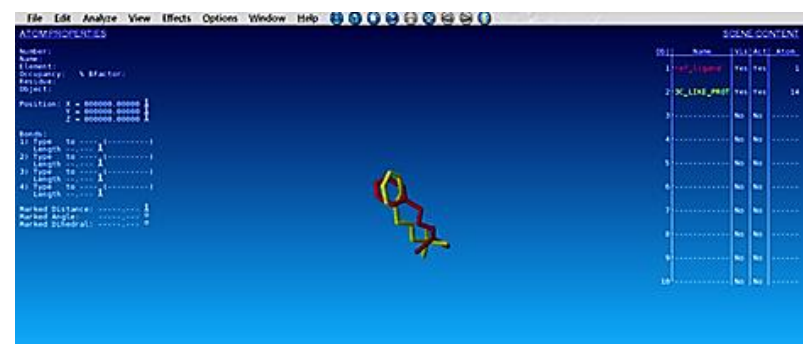

B

Figure 3. RMSD value of (A) PLpro $(0.5707 \AA)$ and (B) $3 C^{\text {pro }}$ $(1.5525 \AA)$.

Interaction with 3CLpro shows demethoxycurcumin was the most potent inhibitor of 3CLpro. The docking score of demethoxycurcumin (-87.1625) was less than remdesivir triphosphates (-86.1811). Sharma et al. ${ }^{24}$ reported that demethoxycurcumin was one of the best inhibitors of $3 C^{\text {pro }}$ with $\Delta \mathrm{G}$ of $-7.02 \mathrm{kcal} / \mathrm{mol}$. This result was based on in silico study using AutoDock 4 to assess some medicinal plants metabolites as 3CLpro inhibitor.

Curcuminoids in both plants have been shown to have antiviral activity, in which curcumin shows antiviral activity in HIV as a protease inhibitor in HIV-1 and HIV-2 based on in vitro and in vivo studies ${ }^{25}$. Other studies suggest that curcumin shows the activity as a SARS-CoV-2 3CL pro and spike protein inhibitor based on molecular docking study ${ }^{10,11}$. Curcumin also reported inhibiting $3 \mathrm{CL}^{\text {pro }}$ in SARS-CoV with an $\mathrm{IC}_{50}$ of 3.3 to $10 \mu \mathrm{M}^{26}$.

\section{Psidium guajava}

The docking score between luteolin, apigenin, quercetin, and kaempferol with both PLpro and 3CLpro was shown in Figure 5. It turns out that the ligands were not potent enough as a PLpro inhibitor. However, among the four ligands, quercetin had the lowest docking score of -80.286 . Interaction with 3 CLpro shows that luteolin (-73.4345), apigenin (-70.3368), quercetin (71.5539), and kaempferol (-68.4321) had potency as 3 CLpro inhibitor, although the docking score was still higher than remdesivir triphosphate (-86.1811). Previous in silico research has shown that based on the free binding energy data, apigenin, luteolin, and quercetin had more potential as 3CL pro inhibitors (-7.4; -7.12; and $-6.83 \mathrm{kcal} / \mathrm{mol}$, respectively) than as PLpro inhibitor $(-6.6 ;-6.9 \text {; and }-6.6 \mathrm{kcal} / \mathrm{mol})^{23}$.

\section{Phyllanthus niruri}

The docking score of formononetin-7-O-glucuronide with PLpro and 3CLpro was presented in Figure 6. The docking score data shows that formononetin-7-Oglucuronide might not have potency as a PLpro inhibitor but had potency as an inhibitor of 3CLpro because the docking score (-72.0154) was less than native ligand (-64.0074) but higher than remdesivir triphosphate (-86.1811). Docking between formononetin-7-O-glucuronide and the receptor for SARS-CoV-2 has not been previously reported, whereas another similar study using a metabolite of $P$. niruri chose nirurin as the test ligand ${ }^{27}$.

\section{Andrographis paniculata}

Andrographis paniculata was an Indonesian plant with the main metabolite in lactone terpenoids such as andrographolide and neoandrographolide ${ }^{28}$. The docking score of andrographolide and neoandrographolide with PLpro and 3CL pro was shown in Figure 7. Based on the results, both andrographolide (-79.1989) and neoandrographolide (-97.2452) had no potency as PLpro inhibitors. On the contrary, the interaction between neoandrographolide with 3CLpro shows the docking score (-93.7746) less than remdesivir triphosphate (-86.1811) and could act as the most potent ligand for 3CLro inhibitor. Murugan et al. ${ }^{14}$ reported that in the in silico research using AutoDock Vina, neoandrographolide had $\Delta \mathrm{G}$ as $3 C L^{\text {pro }}(-31.4 \mathrm{kcal} / \mathrm{mol})$, PLpro (-28.5 kcal/mol), RdRp ($17.1 \mathrm{kcal} / \mathrm{mol})$, and spike protein $(-23.9 \mathrm{kcal} / \mathrm{mol})$ inhibitors, in which they were best for $3 \mathrm{CL}^{\text {pro }}$ inhibitor. In addition, andrographolide was the main antiviral compound that was often found in A. paniculat $a^{29}$. This compound could inhibit the dengue virus in HeLa (EC50 $22.739 \mu \mathrm{M})$ and HepG2 (EC50 $21.304 \mu \mathrm{M})$ cells $^{30}$. 


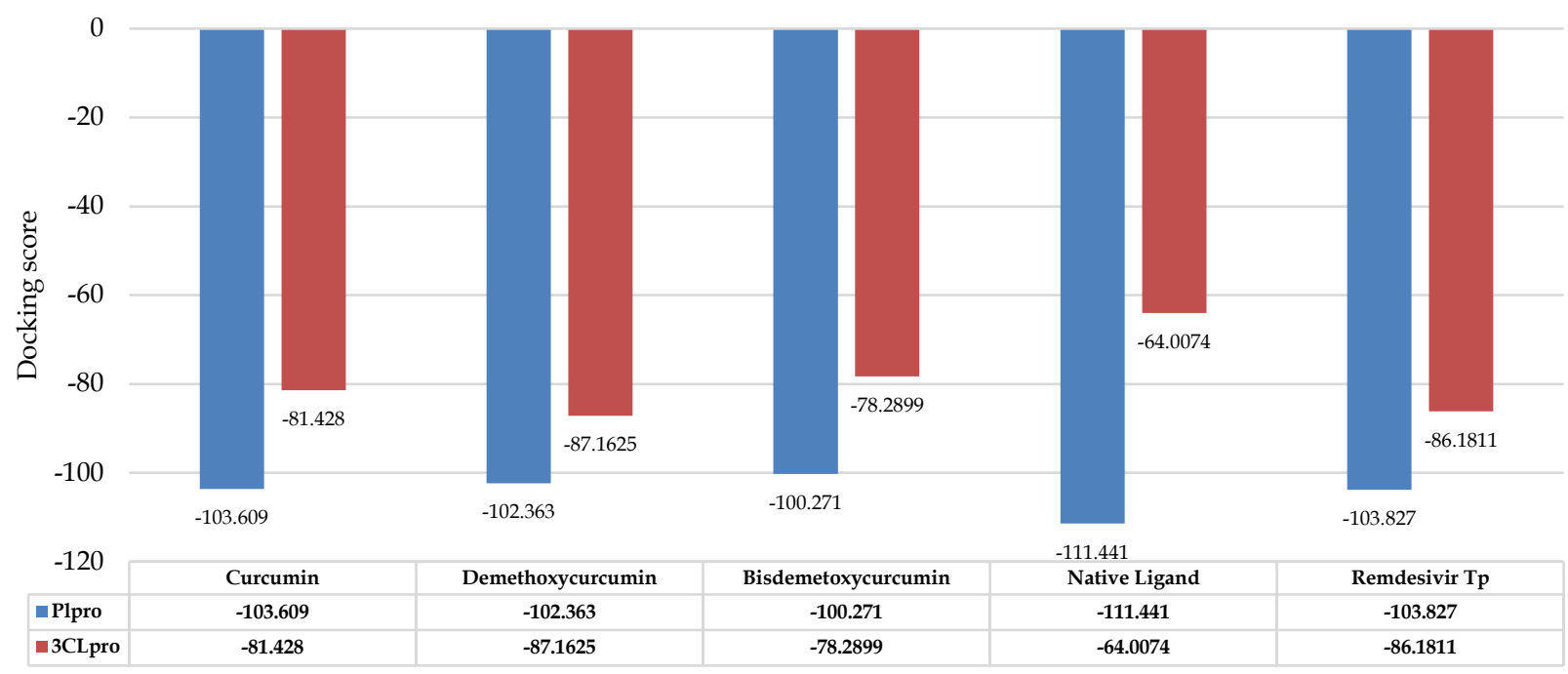

Figure 4. Docking score of curcumin, demethoxycurcumin, and bisdemethoxycurcumin.

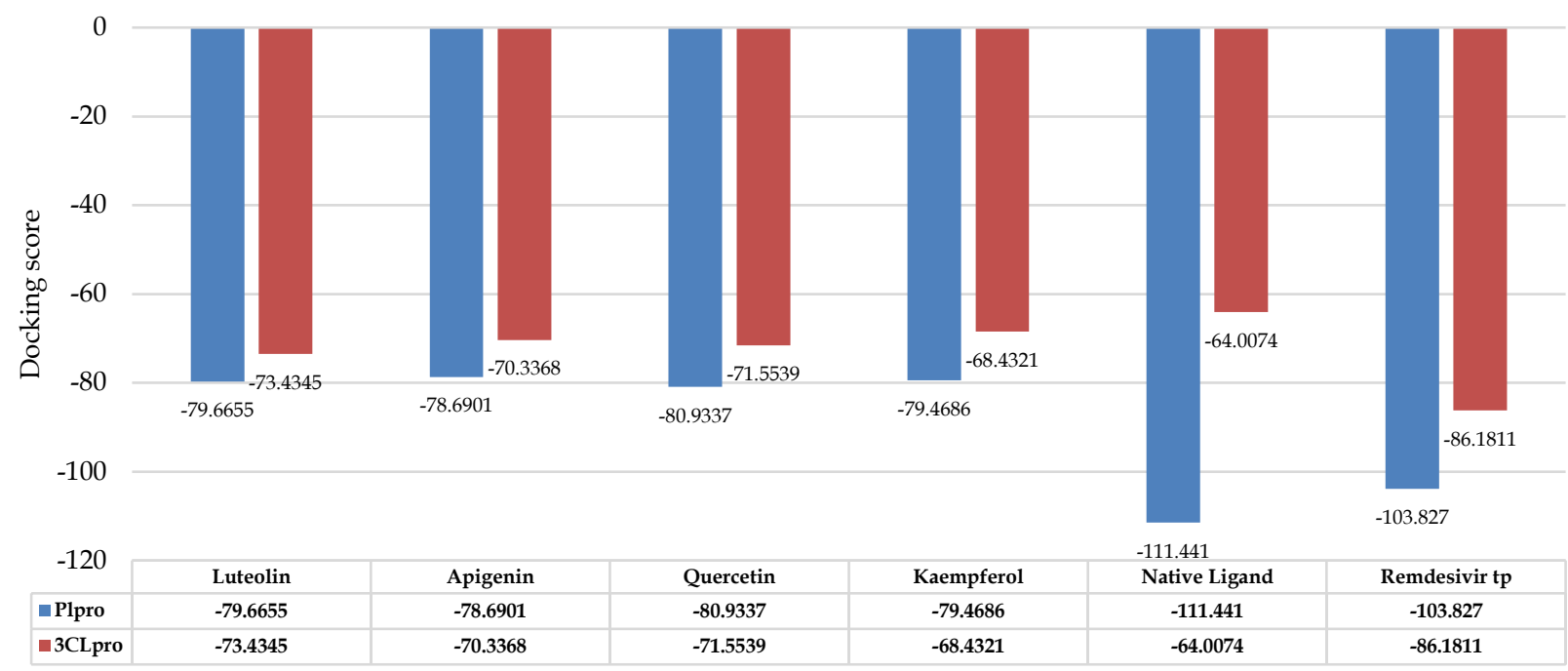

Figure 5. Docking score of luteolin, apigenin, quercetin and kaempferol.

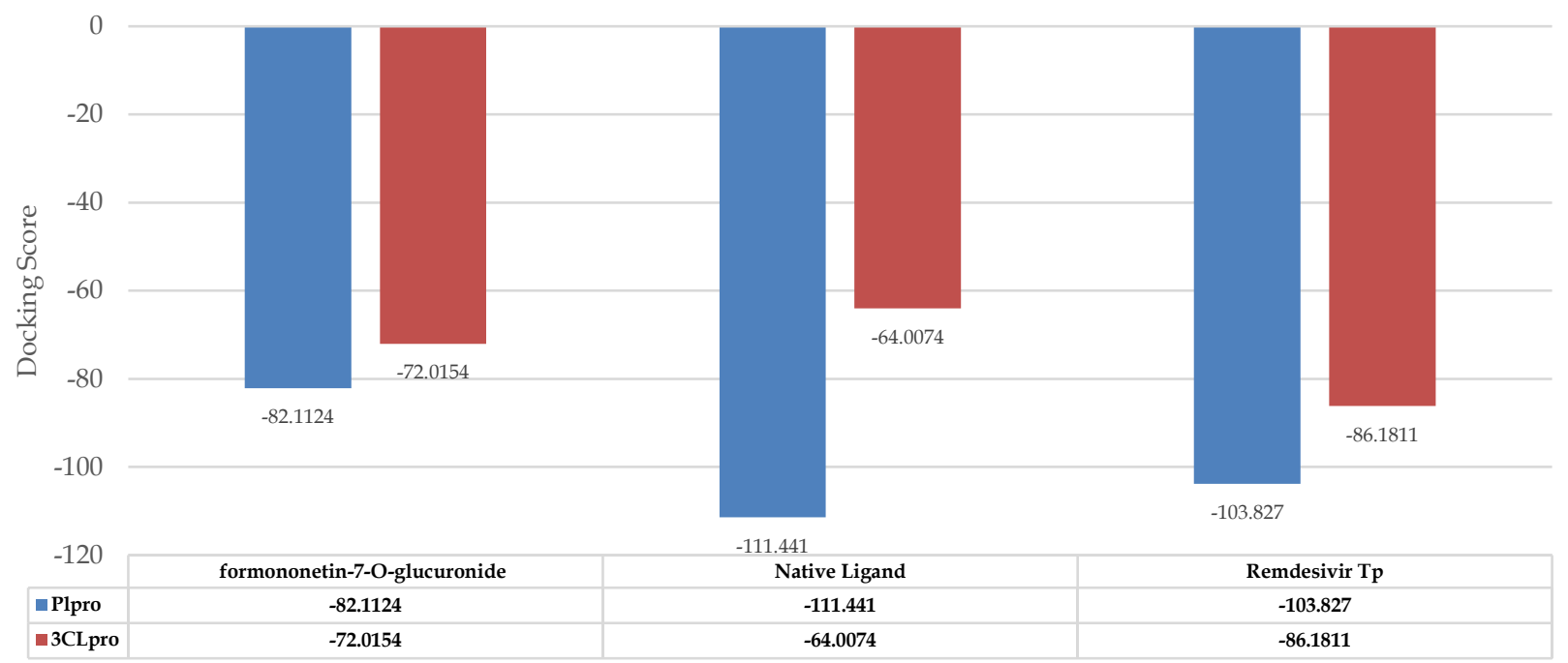

Figure 6. Docking score of formononetin-7-O-glucuronide. 


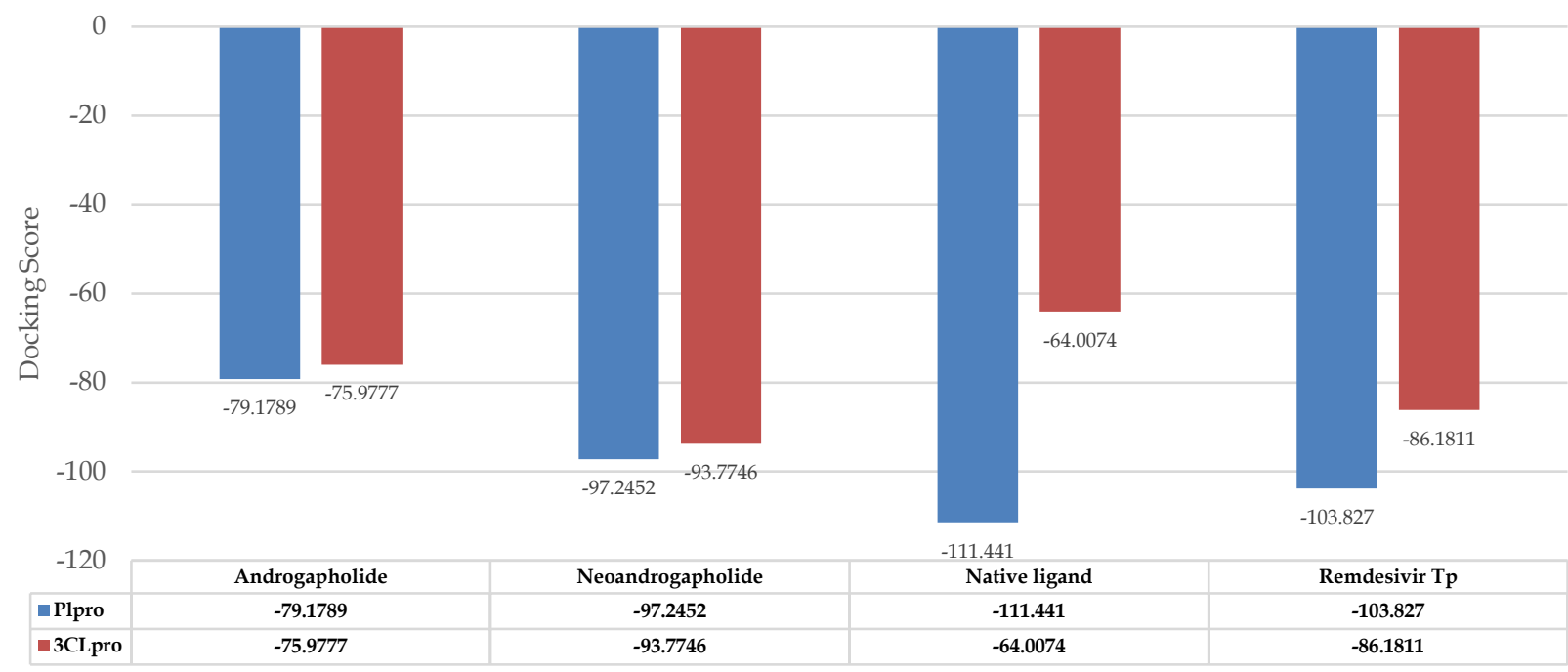

Figure 7. Docking score of andrographolide and neoandrographolide.

Based on the docking score of test ligands with PLpro, curcumin was the most potent inhibitor of PLpro with the lowest docking score of -103.609 , while apigenin was the ligand with the highest docking score, as shown in Table I. This result indicates that curcumin had a good affinity when the interaction occurred between the ligand and PLpro. Based on the docking score, neoandrographolide was the ligand with the lowest docking score of -93.7746, while kaempferol was the highest with -68.4321 . The docking score of neoandrographolide indicated a good affinity with $3 \mathrm{CL}^{\text {pro }}$ and potency to acted as the most potent ligand to inhibit 3CL pro. Curcumin and neoandrographolide were stated as the most potent candidate for PLpro and 3CL pro inhibitors, respectively.

Table I. Docking score of test ligands with PLpro and 3CLpro

\begin{tabular}{lrc}
\hline \multirow{2}{*}{ Ligands } & \multicolumn{2}{c}{ Docking score } \\
\cline { 2 - 3 } & PLpro & 3CLpro \\
\hline Native ligand & -111.441 & -64.0074 \\
Remdesivir triphosphate & -103.827 & -86.1811 \\
Apigenin & -78.6901 & -70.3368 \\
Andrographolide & -79.1789 & -75.9777 \\
Kaempferol & -79.4686 & -68.4321 \\
Luteolin & -79.6655 & -73.4345 \\
Quercetin & -80.9337 & -71.5539 \\
Formononetin-7-O-glucuronide & -82.1124 & -72.0154 \\
Neoandrographolide & -97.2452 & -93.7746 \\
Bisdemethoxycurcumin & -100.271 & -78.2899 \\
Demethoxycurcumin & -102.363 & -87.1625 \\
Curcumin & -103.609 & -81.428 \\
\hline
\end{tabular}

The prediction from this research could be used to develop an anti-COVID-19 drug from herbal compounds such as combination with extract or isolate that contains curcumin and neoandrographolide as the main compounds.
Moreover, combining these two compounds could enhance the inhibitor effect in PLpro or 3CL pro of SARS$\mathrm{CoV}-2$. However, further in vitro and in vivo research was required to confirm this finding.

\section{CONCLUSION}

Based on the docking score, it can be concluded that curcumin has the most potential as a PLpro inhibitor, while neoandrogapholide has the most potential as a 3CL pro inhibitor.

\section{CONFLICTS OF INTEREST}

The authors have no conflicts of interest to declare that are relevant to the content of this article.

\section{FUNDING}

None.

\section{DATA AVAILABILITY}

All data are available from the authors.

\section{ACKNOWLEDGMENTS}

None.

\section{AUTHORS' CONTRIBUTIONS}

Baiq Ressa Puspita Rizma: conceptualization, data curation, formal analysis, funding acquisition, investigation, methodology, software, supervision, validation, visualization, writing - original draft, writing - review \& editing. Agus Dwi Ananto: 
software, supervision, writing - original draft, writing - review \& editing. Anggit Listyacahyani Sunarwidhi: supervision, writing - original draft, writing - review \& editing.

\section{REFERENCES}

1. Dhama K, Khan S, Tiwari R, Sircar S, Bhat S, Malik YS, et al. Coronavirus Disease 2019-COVID-19. Clin Microbiol Rev. 2020;33(4):e00028-20. doi:10.1128/CMR.00028-20

2. Frediansyah A, Nainu F, Dhama K, Mudatsir M, Harapan H. Remdesivir and its antiviral activity against COVID-19: A systematic review. Clin Epidemiol Glob Health. 2021;9:123-7. doi:10.1016/j.cegh.2020.07.011

3. Malin JJ, Suárez I, Priesner V, Fätkenheuer G, Rybniker J. Remdesivir against COVID-19 and Other Viral Diseases. Clin Microbiol Rev. 2020;34(1):e00162-20. doi:10.1128/cmr.00162-20

4. Nguyen HL, Thai NQ, Truong DT, Li MS. Remdesivir Strongly Binds to Both RNADependent RNA Polymerase and Main Protease of SARS-CoV-2: Evidence from Molecular Simulations. J Phys Chem B. 2020;124(50):11337-48. doi:10.1021/acs.jpcb.0c07312

5. Bailly C, Vergoten G. Glycyrrhizin: An alternative drug for the treatment of COVID-19 infection and the associated respiratory syndrome? Pharmacol Ther. 2020;214:107618. doi:10.1016/j.pharmthera.2020.107618

6. Lin X, Li X, Lin X. A Review on Applications of Computational Methods in Drug Screening and Design. Molecules. 2020;25(6):1375. doi:10.3390/molecules25061375

7. Batool M, Ahmad B, Choi S. A Structure-Based Drug Discovery Paradigm. Int J Mol Sci. 2019;20(11):2783. doi:10.3390/ijms20112783

8. Attique SA, Hassan M, Usman M, Atif RM, Mahboob S, Al-Ghanim KA, et al. A Molecular Docking Approach to Evaluate the Pharmacological Properties of Natural and Synthetic Treatment Candidates for Use against Hypertension. Int J Environ Res Public Health. 2019;16(6):923. doi:10.3390/ijerph16060923

9. Badan Pengawas Obat dan Makanan Republik Indonesia. Pedoman Penggunaan Herbal dan Suplemen Kesehatan dalam Menghadapi COVID-
19 di Indonesia. Jakarta: Badan Pengawas Obat dan Makanan Republik Indonesia; 2020.

10. Jena AB, Kanungo N, Nayak V, Chainy GBN, Dandapat J. Catechin and curcumin interact with $S$ protein of SARS-CoV2 and ACE2 of human cell membrane: insights from computational studies. Sci Rep. 2021;11(1):2043. doi:10.1038/s41598-021$81462-7$

11. Gupta S, Singh AK, Kushwaha PP, Prajapati KS, Shuaib M, Senapati $S$, et al. Identification of potential natural inhibitors of SARS-CoV2 main protease by molecular docking and simulation studies. J Biomol Struct Dyn. 2020:1-12. doi:10.1080/07391102.2020.1776157

12. Park JY, Yuk HJ, Ryu HW, Lim SH, Kim KS, Park $\mathrm{KH}$, et al. Evaluation of polyphenols from Broussonetia papyrifera as coronavirus protease inhibitors. J Enzyme Inhib Med Chem. 2017;32(1):504-15. doi:10.1080/14756366.2016.1265519

13. Jo S, Kim S, Shin DH, Kim MS. Inhibition of SARS$\mathrm{CoV} 3 \mathrm{CL}$ protease by flavonoids. J Enzyme Inhib Med Chem. 2020;35(1):145-51. doi:10.1080/14756366.2019.1690480

14. Murugan NA, Pandian CJ, Jeyakanthan J. Computational investigation on Andrographis paniculata phytochemicals to evaluate their potency against SARS-CoV-2 in comparison to known antiviral compounds in drug trials. J Biomol Struct Dyn. 2020:1-12. doi:10.1080/07391102.2020.1777901

15. Tsai SC, Lu CC, Bau DT, Chiu YJ, Yen YT, Hsu YM, et al. Approaches towards fighting the COVID-19 pandemic (Review). 2021; Int J Mol Med. 47(1):3-22. doi:10.3892/ijmm.2020.4794

16. Naqvi AAT, Fatima K, Mohammad T, Fatima U, Singh IK, Singh A, et al. Insights into SARS-CoV-2 genome, structure, evolution, pathogenesis and therapies: Structural genomics approach. Biochim Biophys Acta Mol Basis Dis. 2020;1866(10):165878. doi:10.1016/j.bbadis.2020.165878

17. Shin D, Mukherjee R, Grewe D, Bojkova D, Baek K, Bhattacharya A, et al. Papain-like protease regulates SARS-CoV-2 viral spread and innate immunity. Nature. 2020;587(7835):657-62. doi:10.1038/s41586-020-2601-5 
18. Wang R, Stephen P, Tao Y, Zhang W, Lin SX. Human endeavor for anti-SARS-CoV-2 pharmacotherapy: A major strategy to fight the pandemic. Biomed Pharmacother. 2021;137:111232. doi:10.1016/j.biopha.2021.111232

19. Douangamath A, Fearon D, Gerhtz P, Krojer T, Lukacik P, Owen CD, et al. Crystallographic and electrophilic fragment screening of the SARS-CoV2 main protease. Nat Commun. 2020;11(1):5047. doi:10.1038/s41467-020-18709-w

20. Purnomo H, Jenie UA, Nugroho AE, Pranowo HD. In silico and in vivo qualitative relationships of para-aminophenol analogues. Int J Pharm Clin Res. 2016;8(Suppl 5):367-71.

21. Castro-Alvarez A, Costa AM, Vilarrasa J. The Performance of Several Docking Programs at Reproducing Protein-Macrolide-Like Crystal Structures. Molecules. 2017;22(1):136. doi:10.3390/molecules22010136

22. Meng XY, Zhang HX, Mezei M, Cui M. Molecular Docking: A powerful approach for structure-based drug discovery. Curr Comput Aided Drug Des. 2011;7(2):146-57. doi:10.2174/157340911795677602

23. Laksmiani NPL, Larasanty LPF, Santika AAGJ, Prayoga PAA, Dewi AAIK, Dewi NPAK. Active Compounds Activity from the Medicinal Plants Against SARS-CoV-2 using in Silico Assay. Biomed Pharmacol J. 2020;13(2):873-81. doi:10.13005/bpj/1953

24. Sharma A, Goyal S, Yadav AK, Kumar P, Gupta L. In-silico screening of plant-derived antivirals against main protease, 3CLpro and endoribonuclease, NSP15 proteins of SARS-CoV-2. J Biomol Struct Dyn. 2020:1-15. doi:10.1080/07391102.2020.1808077

25. Moghadamtousi SZ, Kadir HA, Hassandarvish P, Tajik H, Abubakar S, Zandi K. A review on antibacterial, antiviral, and antifungal activity of curcumin. Biomed Res Int. 2014;2014:186864. doi:10.1155/2014/186864

26. Wen CC, Kuo YH, Jan JT, Liang PH, Wang SY, Liu HG, et al. Specific plant terpenoids and lignoids possess potent antiviral activities against severe acute respiratory syndrome coronavirus. J Med Chem. 2007;50(17):4087-95. doi:10.1021/jm070295s

27. Puttaswamy H, Gowtham HG, Ojha MD, Yadav A, Choudhir G, Raguraman V, et al. In silico studies evidenced the role of structurally diverse plant secondary metabolites in reducing SARSCoV-2 pathogenesis. Sci Rep. 2020;10(1):20584. doi:10.1038/s41598-020-77602-0

28. Okhuarobo A, Falodun JE, Erharuyi O, Imieje V, Falodun A, Langer P. Harnessing the medicinal properties of Andrographis paniculata for diseases and beyond: a review of its phytochemistry and pharmacology. Asian Pac J Trop Dis. 2014;4(3):21322. doi:10.1016/S2222-1808(14)60509-0

29. Enmozhi SK, Raja K, Sebastine I, Joseph J. Andrographolide as a potential inhibitor of SARS$\mathrm{CoV}-2$ main protease: an in silico approach. $\mathrm{J}$ Biomol Struct Dyn. 2020:1-7. doi:10.1080/07391102.2020.1760136

30. Saleh MSM, Kamisah Y. Potential Medicinal Plants for the Treatment of Dengue Fever and Severe Acute Respiratory Syndrome-Coronavirus. Biomolecules. 2020;11(1):42. doi:10.3390/biom11010042 